\title{
Changes in Thalamus-Hypothalamus Serotonin Transporter Availability during Clomipramine Administration in Patients with Obsessive-Compulsive Disorder
}

\author{
Werner Zitterl',', Martin Aigner', Thomas Stompe', Karin Zitterl-Eglseer', Karin Gutierrez-Lobos', \\ Thomas Wenzel', Georg Zettinig ${ }^{3}$, Kurt Hornik ${ }^{4}$, Walter Pirker ${ }^{5}$ and Kenneth Thau' \\ 'Department of Psychiatry, Medical University of Vienna, Vienna, Austria; ${ }^{2}$ Department of Public Health, University of Veterinary Medicine, \\ Vienna, Austria; ${ }^{3}$ Department of Nuclear Medicine, Medical University of Vienna, Vienna, Austria; ${ }^{4}$ Department of Statistics and Mathematics, \\ Vienna University of Economics and Business Administration, Vienna, Austria; ${ }^{5}$ Department of Neurology, Medical University of Vienna, Vienna, \\ Austria
}

To the authors' knowledge there is as of yet no study demonstrating in vivo alterations in human serotonin transporters (SERT) during clomipramine treatment in patients with obsessive-compulsive disorder. The only study in which SERT binding has been investigated in obsessive-compulsive disorder (OCD) patients before and after treatment is a small pilot study by Stengler-Wenzke et al (2006), who treated five OCD patients with citalopram. In the study at hand, we measured transporter availability in the thalamus-hypothalamus with $\left[{ }^{123} \mathrm{I}\right] \beta$-CIT single photon emission computed tomography (SPECT) in 24 patients with DSM-IV OCD. All patients displayed prominent behavioral checking compulsions (OC-checkers). At baseline and upon medication after 12 weeks of treatment with clomipramine ( $50 \mathrm{mg}$ daily) 24 non-depressed OC-checkers underwent a SPECT measurement of brain SERT availability using $\left[{ }^{123} \mid\right]-2 \beta$-carbomethoxy-3 $\beta$-(4-iodophenyl)tropane. For quantification of brain serotonin transporter availability, a ratio of specific to nondisplaceable $\left[{ }^{123} \mid\right] \beta$-CIT brain binding was used $\left(B P_{\mathrm{ND}}=\right.$ (thalamus and hypothalamus-cerebellum)/cerebellum). The SERT availability was compared between baseline and after treatment and correlated with severity of $O C$ symptomatology and treatment response as assessed with the Yale-Brown Obsessive Compulsive Scale (Y-BOCS). After treatment with clomipramine patients showed a 48\% reduced brain serotonin transporter availability in the thalamus-hypothalamus, as compared with values at baseline (0.72 \pm 0.12 vs $1.39 \pm 0.18, p<0.001$ ). Correlations between brain SERT availability and OC symptomatology (Y-BOCS scores) revealed significantly negative associations both at baseline and after treatment $(r=-0.46 ; p<0.05$ and $r=-0.53 ; p<0.0$ I respectively). These data suggest that the SERT availability values could be considered a biological indicator of disease severity. Moreover, in search of predictors we found that higher pretreatment SERT availability significantly predicted better treatment response 12 weeks later $(B=|4.145 \pm 4.5| 4$; $t=3.133 ; p=0.005)$. These results provide further support for an important role of alterations in serotonergic neurons in the pathophysiology of OCD.

Neuropsychopharmacology (2008) 33, 3126-3 I34; doi:I0.1038/npp.2008.35; published online 19 March 2008

Keywords: SPECT; $\left[{ }^{123} \mathrm{I}\right] \beta$-CIT; serotonin transporter; thalamus; clomipramine; obsessive-compulsive disorder

\section{INTRODUCTION}

Obsessive-compulsive disorder (OCD) is a clinically defined condition characterized by intrusive and distressing thoughts, images or impulses (obsessions) and by repetitive mental or behavioral acts (compulsions).

At some point during the course of the disorder, patients recognize that these obsessions and compulsions are

*Correspondence: Ass. Professor. W Zitterl, Department of Psychiatry, Medical University of Vienna, Währinger Gürtel I 8-20, Vienna A- 1090 , Austria. Tel: +43 | 40400 3568, Fax: + 43 | 40400 3560,

E-mail: werner.zitterl@meduniwien.ac.at

Received 4 June 2007; revised 29 January 2008; accepted I 5 February 2008 unreasonable and products of their own mind. Once considered rare, recent epidemiological data suggest prevalence rates of OCD from 1.5 to $3.5 \%$ (Stein et al, 1997; Horwath and Weissman, 2000; Angst et al, 2004). Neuropsychiatric research of the past two decades with advanced neuroimaging techniques and neurophysiological and pharmacologic studies has provided growing evidence for a neurobiological basis of OCD (Goodman et al, 1992; Hollander et al, 1992; Insel, 1992; Prichep et al, 1993; Saxena et al, 1998; Saxena and Rauch, 2000). The current pathophysiological concepts point toward neurochemical abnormalities of central serotonergic functioning. In general, OCD symptoms can best be managed with the serotonin reuptake inhibitor clomipramine, the selective serotonin reuptake inhibitors (SSRIs) or behavioral therapy 
(Leonard et al, 1988; Goodman, 1999; Vythilingum et al, 2000). The selective response of OCD patients to clomipramine or SSRIs has led to the hypothesis that changes in the central serotonergic systems may be the mechanism by which these compounds exert their effect (Leonard et al, 1988; Goodman et al, 1990, 1992; Baumgarten and Grozdanovic, 1998). Direct evidence that serotonergic perturbations are implicated in the neurobiology of OCD; however, is sparse (Stein, 2002).

The main property of clomipramine is the inhibition of neuronal reuptake of norepinephrine and serotonin released in the synaptic cleft, the inhibition of serotonin uptake being its predominant effect. The effect is attained by blocking of serotonin transporters, which are located presynaptically, resulting in an increasing concentration of serotonin at receptor sites. Additionally, clomipramine is characterized by a broad pharmacological spectrum of actions including $\alpha_{1}$-adrenolytic, anticholinergic, and weak antihistaminergic and antiserotonergic (serotonin-receptor blocking) properties. The actual neurochemical mechanism is unknown, but clomipramine's capacity to inhibit serotonin reuptake is thought to be important (McTavish and Benfield, 1990; Suhara et al, 2003).

Neuroimaging studies have been very influential in shaping neurobiological models of OCD. Converging data have implicated a network of brain regions, including the orbitofrontal cortex, striatum, and thalamus, in the pathophysiology of OCD. Most regions of the putatively involved network in OCD are densely innervated by serotonergic or dopaminergic neurons (Insel, 1992). However, despite the advent of several ligands for dopaminergicand serotonergic-binding sites suitable for positron emission tomography (PET) or single photon emission computed tomography (SPECT), the functional anatomy of these neurotransmitter systems in OCD has scarcely been investigated. A commonly used ligand is 123 -I-labeled $2-\beta$ carbomethoxy-3- $\beta$-(4-iodophenyl)-tropane ([ $\left.{ }^{123} \mathrm{I}\right] \beta$-CIT), a SPECT ligand enabling both serotonin (5-HT) and dopamine transporter visualization in the brain (Innis et al, 1991; Boja et al, 1992; Kuikka et al, 1993; Brücke et al, 1993; Pirker et al, 2000). $\left[{ }^{123} \mathrm{I}\right] \quad \beta$-CIT has already been used extensively to investigate several psychiatric and neuropsychiatric disorders (Malison et al, 1998; Heinz et al, 1998a, b; Willeit et al, 2000; Jacobsen et al, 2000; Tauscher et al, 2001; Kasper et al, 2002). Binding of $\left[{ }^{123} \mathrm{I}\right] \beta$-CIT in the striatal region has been shown to reflect mainly binding to dopamine transporter whereas binding to serotonin transporter occurs predominantly in the thalamus, midbrain, and pons.

To the authors' knowledge, there have been seven studies investigating human serotonin transporters (SERT) availability in untreated OCD patients published to date: two PET studies and five $\beta$-CIT SPECT studies (Simpson et al, 2003; van der Wee et al, 2004; Pogarell et al, 2003; StenglerWenzke et al, 2004; Hesse et al, 2005; Reimold et al, 2007; Zitterl et al, 2007). The authors are not aware of any studies examining SERT availability in treated OCD patients with the exception of a pilot study of Stengler-Wenzke et al (2006), who treated five OCD patients with citalopram.

The present study sought to examine possible differences in $\left[{ }^{123} \mathrm{I}\right] \beta$-CIT-binding patterns in OCD patients before and after treatment with clomipramine. As patients diagnosed with obsessive-compulsive disorder often represent a very heterogeneous group clinically, only OC-checkers were enrolled in this study to obtain as homogeneous a patient group as possible. These OC-checkers did not display any clinically relevant depressive symptomatology.

We hypothesized that the binding patterns of $\left[{ }^{123} \mathrm{I}\right] \beta$-CIT in OCD patients treated with clomipramine would reflect a marked reduction in SERT availability in the thalamichypothalamic region as compared to the control value at baseline. This hypothesis was drawn from the $\beta$-CIT study by Fujita et al (1997), in which the binding potential of SERT in the hypothalamus in rat brain after administration of clomipramine was decreased to $35 \%$ of the control value. Thus, the present study is to our knowledge the first in vivo visualization of the effect of the serotonin reuptake inhibitor, clomipramine, in patients with OCD by means of $\beta$-CIT and SPECT.

\section{PATIENTS AND METHODS}

\section{Subjects}

The study population consisted of 24 non-depressed patients diagnosed with a DSM-IV obsessive-compulsive disorder (American Psychiatric Association, 1994), 11 female patients and 13 male patients, ranging in age from 20 to 58 years. These patients were newly recruited solely for the study at hand, the data of whom have not been used in previous publications. The mean age was $38.8 \pm 11.2$ years and the mean age at onset of illness $22.6 \pm 10.0$ years (Table 1). All OCD patients were OC-checkers, whose main symptomatology was required to consist of compulsive checking rituals. They were consecutively recruited from the specialized outpatient clinic for OCD of the Department of

Table I Mean $( \pm \mathrm{SD})$ Thalamus-Hypothalamus $\beta$-CIT-Binding Ratios ([Thalamus and Hypothalamus-Cerebellum]/Cerebellum), Demographic and Clinical Data of 24 OCD Patients Treated with Clomipramine

\begin{tabular}{|c|c|c|c|}
\hline & \multicolumn{3}{|c|}{ Patients } \\
\hline & All patients & Female & Male \\
\hline$n$ & 24 & 11 & 13 \\
\hline Age (years) & $38.8 \pm 11.2$ & $39.5 \pm 10.4$ & $38.2 \pm 12.2$ \\
\hline Age at onset (years) & $22.6 \pm 10.0$ & $24.5 \pm 9.5$ & $21.0 \pm 10.5$ \\
\hline \multicolumn{4}{|l|}{ Y-BOCS } \\
\hline Baseline & $26.2 \pm 4.9$ & $25.8 \pm 5.1$ & $26.5 \pm 4.0$ \\
\hline After 12 weeks treatment & $18.9 \pm 6.7$ & $17.9 \pm 8.2$ & $19.7 \pm 5.2$ \\
\hline Treatment response (Improvement) & $7.3 \pm 5.0$ & $7.9 \pm 5.3$ & $6.9 \pm 4.9$ \\
\hline \multicolumn{4}{|l|}{$\beta$-CIT binding ratios } \\
\hline Baseline & $1.39 \pm 0.18$ & $1.38 \pm 0.21$ & $1.40 \pm 0.16$ \\
\hline After 12 weeks treatment & $0.72 \pm 0.12^{\mathrm{a}}$ & $0.74 \pm 0.10^{\mathrm{a}}$ & $0.71 \pm 0.13^{\mathrm{a}}$ \\
\hline
\end{tabular}


Psychiatry, University Hospital of Vienna. All patients were non-smokers. Alcohol consumption was not allowed from 1 week prior to initiation of the study until completion.

Demographic and clinical information on the longitudinal course of illness, previous treatment attempts, and other psychiatric diagnoses were obtained using the Structured Clinical Interview for DSM-IV (SCID-1; First et al, 1996) and by reviewing medical records and contacting previous psychiatrists directly. Axis II diagnoses were assessed based on clinical interview. Patients with present or past Axis I or Axis II psychiatric diagnoses other than OCD were not included in the study. The patients were diagnosed by consensus of the authors using DSM-IV criteria for OCD and had displayed prominent behavioral checking compulsions for a duration of at least 2 years. All patients had been free of psychotropic agents for at least 6 months prior to the investigation. No patient had been treated with other somatic treatments (eg, electroconvulsive therapy). Urine $\beta$-HCG tests were performed to exclude pregnancy in female subjects.

Further inclusion criteria were a score on the Yale-Brown Obsessive Compulsive Scale (Y-BOCS) (Goodman et al, $1989 \mathrm{a}, \mathrm{b})$ of at least 16 and a maximum Hamilton Depression Scale score of $13\left(\mathrm{HAMD}_{17}\right)$ (Hamilton, 1960). OCD patients with a main OC symptomatology other than compulsive checking rituals or with depressive symptomatology were excluded from the study.

\section{Treatment Protocol}

The 24 OCD patients received $37.5 \mathrm{mg} /$ day clomipramine in the first and second week, $75 \mathrm{mg} /$ day/clomipramine in the third and fourth week and $150 \mathrm{mg} /$ day from the fifth to the twelfth week. The medication was administered as slowrelease drug once a day in the evening. Compliance with the medication was examined in regular medical interviews and self-reports.

SPECT imaging was performed at baseline and upon medication after 12 weeks of treatment. The rating scales (Y-BOCS and $\mathrm{HAMD}_{17}$ ) were administered likewise at baseline and 12 weeks later. The mean $\mathrm{HAMD}_{17}$ scores were below 7.0 at both measurements and we could not observe any clinically relevant depressive symptomatology in any patient.

The study was approved by the local ethics committee and has been carried out in accordance with the Declaration of Helsinki. Written informed consent for participation in this study was obtained from each subject after the procedure had been fully explained by the research physicians of both the Departments of Psychiatry and Nuclear Medicine.

\section{SPECT Imaging and Data Analysis}

$\left[{ }^{123} \mathrm{I}\right] \beta$-CIT was synthesized according to the method of Neumeyer et al (1991) with several modifications described earlier (Brücke et al, 1993). After blockade of thyroid uptake with $600 \mathrm{mg}$ sodium perchlorate orally $30 \mathrm{~min}$ before tracer application, subjects received a mean dose of $132 \mathrm{MBq}$ ( $\pm 18 \mathrm{SD} ; 3.6 \mathrm{mCi} \pm 0.5 \mathrm{SD})\left[{ }^{123} \mathrm{I}\right] \beta$-CIT intravenously as a single bolus. The SPECT-studies were performed $4 \mathrm{~h}$ after tracer injection using a triple-headed rotating scintillation camera (Siemens Multispect 3, Knoxville, TN, USA) with a resolution of $9 \mathrm{~mm}$ full width at half maximum in the transaxial plane. Camera heads were equipped with medium energy collimators. The subject's head was placed in the head holder with the aide of a laser beam system with the infraorbitomeatal plane aligned perpendicular to the rotational axis. A chin-strap device was used to minimize movement of the head during the scan. Data acquisition and analysis were performed using the ICON software package for the Siemens Multispect 3 camera. For each scan, a total of 180 frames were collected in a step and shoot mode. SPECT imaging lasted for $20 \mathrm{~min}$ ( $20 \mathrm{~s}$ per frame).

$3.5 \mathrm{~mm}$-thick cross sections, oriented parallel to the canthomeatal plane, were reconstructed by filtered back projection (Butterworth filter, cutoff frequency 0.7, order 7) in $128 \times 128$ matrices. Attenuation correction was performed assuming uniform attenuation within an ellipse drawn around the head contour (attenuation coefficient $=$ $0.120 / \mathrm{cm}$ ). Circular regions of interest (ROIs) were placed in a midline area corresponding to the thalamus and hypothalamus (size: 32 voxels each; voxel size $3.5 \times 3.5 \times$ $3.5 \mathrm{~mm}$ ) on 5-6 consecutive axial sections (Figure 1). Irregular ROIs were drawn in areas corresponding to the left and right cerebellar hemisphere (60 voxels each). All ROIs were drawn with the help of a brain atlas (Talairach and Tournoux, 1988) by one and the same examiner, who was blind to the clinical status of the subjects. Values of the four circular midline ROIs with the highest count rate (usually from one slice below the maximum of striatal binding downwards; area corresponding to thalamus and hypothalamus) were pooled together to form a 'thalamushypothalamus' region (constant volume of interest $5.5 \mathrm{~cm}^{3}$ ) and the average counts/voxel were calculated. Values of both cerebellar ROIs in three consecutive axial slices of maximal cerebellar activity were averaged. Cerebellar activity was assumed to represent nonspecific bound and free activity as it is known that the density of DAT and SERT in the cerebellum is very low (Bäckström et al, 1989; De Keyser et al, 1989).

Ratios between mean counts in the target region (thalamus and hypothalamus) and the cerebellum were calculated. This ratio minus one ((region/cerebellum) -1$)$, denoted as $V_{3}^{\prime \prime}$ (Laruelle et al, 1994) or $B P_{\mathrm{ND}}$, according to the new consensus terminology (Innis et al, 2007), represents specific/non-displaceable uptake and is assumed to be directly related to the binding potential (Mintun et al, 1984; Laruelle et al, 1994; Malison et al, 1998).

The SPECT acquisition time of $4 \mathrm{~h}$ post injection used in the present study and in the studies by van der Wee et al (2004) and Zitterl et al (2007) differed from several previous studies, where imaging was performed at 20 or $24 \mathrm{~h}$ post injection (Pogarell et al, 2003; Stengler-Wenzke et al, 2004, 2006; Hesse et al, 2005). Kinetic studies of $\beta$-CIT uptake in SERT-rich brain areas showed a peak in tracer uptake in the thalamus-hypothalamus at $4 \mathrm{~h}$ post injection, followed by stable uptake up to $10 \mathrm{~h}$, and a slow decrease up to $24 \mathrm{~h}$ post injection. Due to a concomitant slow but steady decline in uptake in the cerebellum from $4 \mathrm{~h}$ onward, a higher stability of binding ratios in SERT-rich brain areas was observed on day 2, suggesting that a state of true equilibrium is reached between 20 and $24 \mathrm{~h}$ (Pirker et al, 2000). However, conditions are close to true equilibrium between 4 and 

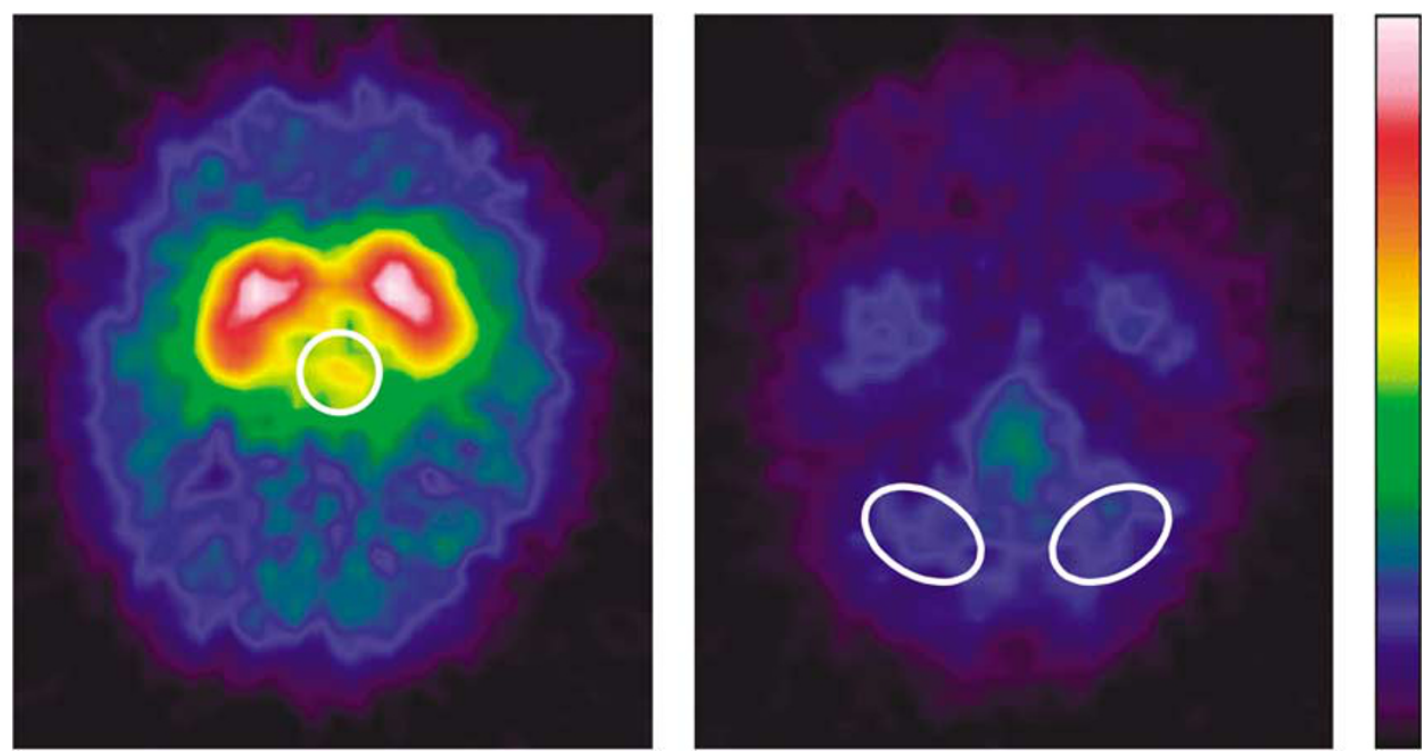

Figure I Axial $\left[{ }^{123} \mid\right] \beta$-CIT SPECT images at the level of the striatum (left) and cerebellum (right) with ROls in the thalamus (left) and the cerebellar hemispheres (right). Image acquisition $4 \mathrm{~h}$ post injection. The level of radioactivity is color coded from black (low) through green, yellow, red and white (high) and scaled to the maximum of the study.

$10 \mathrm{~h}$ post injection. In a study by Pirker et al (1995) the binding reduction in $\beta$-CIT in the thalamus-hypothalamus area in depressed patients treated with citalopram was virtually the same at $4 \mathrm{~h}$ and at $20 \mathrm{~h}$ post injection $(-47 v \mathrm{~s}$ $-45 \%$, respectively), suggesting that both points in time are feasible for the measurement of SERT with $\left[{ }^{123} \mathrm{I}\right] \beta$-CIT SPECT.

\section{Statistical Analysis}

Descriptive analyses of clinical and SPECT variables were given as means and standard deviations. Two-tailed Student $t$-tests were used to compare statistical differences eg between regional $\left[{ }^{123} \mathrm{I}\right] \quad \beta$-CIT uptake in OCD patients before and after treatment with clomipramine. Pearson Product Moment Correlation Coefficients were calculated to study possible correlations between $\left[{ }^{123} \mathrm{I}\right] \beta$-CIT binding and severity of OCD (Y-BOCS scores), age at onset, age and gender. As a control for the effects of age, gender, age at onset of OCD and severity of illness, multiple linear regression analyses were performed with thalamushypothalamus $\beta$-CIT-binding ratios as dependent variable both pre- and posttreatment. Further multiple linear regression analyses were applied to assess the importance of pretreatment factors as predictors of treatment response. Statistical analyses were performed using the Statistical Package for the Social Sciences (SPSS version 12.0.0 for Microsoft Windows, SPSS Inc., Chicago, IL). The $p<0.05$ level was considered statistically significant.

\section{RESULTS}

According to regular interviews and self-reports of the patients, compliance with the medication regimen was very good. All 24 OCD patients followed the fixed dose ratio as described in the section Treatment Protocol. The clomipramine doses at week 12 were $150 \mathrm{mg} /$ day and subjects had been on these doses for 8 weeks (two subjects missed 1 dose during week 3 and 4). There was no variability in the timing of the medication or length of time on the highest dose.

The mean severity of OC symptomatology before treatment (baseline) as measured by Y-BOCS scores was $26.2 \pm 4.9$, ranging from 17 to 35 (Table 1). The treatment response (improvement) in OC symptomatology between baseline and 12 weeks of treatment (Y-BOCS: $18.9 \pm 6.7$ ) was $28 \%(7.3 \pm 5.0)$ on average.

After 12 weeks of treatment with clomipramine, mean radioligand binding to SERT in the thalamus-hypothalamus was significantly reduced by $47.82 \% \pm 9.6$ as compared to baseline values $\left(B P_{\mathrm{ND}}\right.$ SERT: $0.72 \pm 0.12$ vs $1.39 \pm 0.18$; $p<0.001^{* * *}$ ) (Table 1, Figure 2). The individual ratios of specific to non-displaceable $\left[{ }^{123} \mathrm{I}\right] \quad \beta$-CIT binding ranged from 0.99 to 1.71 and 0.52 to 1.00 at baseline and after treatment, respectively, and the individual percent reduction ranged from 23 to $61 \%$. There were no substantial differences between women and men with regard to age, age at onset, Y-BOCS scores or $\beta$-CIT binding ratios at either time of measurement (Table 1).

Correlation analyses of imaging and clinical data showed significant negative associations between $\beta$-CIT binding and obsessive-compulsive scores both at baseline $(r=-0.46$; $\left.p=0.012^{\star}\right)$ and after treatment $\left(r=-0.53 ; p<0.01^{\star *}\right)$ (Figure $3 \mathrm{a}$ and $\mathrm{b}$ ). As multiple factors seem to interfere with SPECT measurements, multiple linear regression analyses were applied to assess the contribution of each independent variable (subject's age, gender, age at onset of OCD and severity of illness) to $\beta$-CIT-binding ratios. These multivariate statistical models showed that, both at baseline and after treatment, the severity of illness had significant impact on $\beta$-CIT binding $(\mathrm{B}=-0.021 \pm 0.004 ; t=-4.918$; $p<0.001$ and $\mathrm{B}=-0.011 \pm 0.002 ; t=-5.432 ; p<0.001$ respectively); the other variables were not significant. 


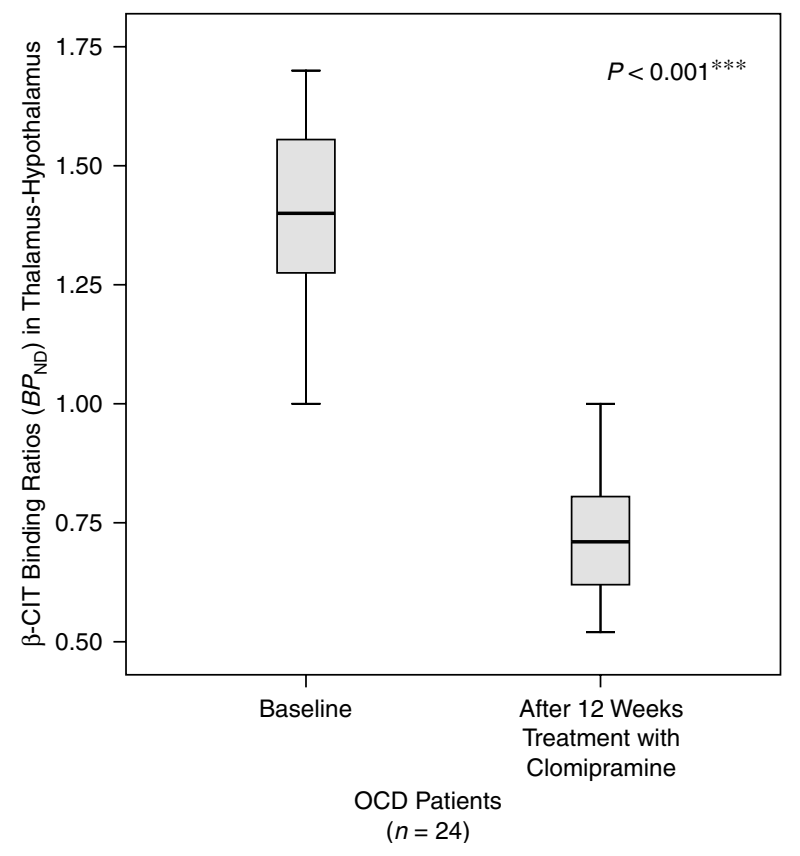

Figure 2 Serotonin transporter availability in thalamus-hypothalamus measured with $\left[{ }^{\mid 23} \mid\right]-2-\beta$-carbomethoxy-3- $\beta$-(4-iodophenyl)-tropane $\left(\left[{ }^{123} \mid\right] \beta\right.$-CIT) single photon emission computer tomography (SPECT) in $24 \mathrm{OCD}$ patients before (baseline) and after 12 weeks of treatment with clomipramine; (Two-tailed t-test; $p<0.00 I^{* * * *}$ ).

In a further step we correlated treatment response (Y-BOCS differences between baseline and after 12 weeks treatment) with pretreatment $\beta$-CIT binding. The data showed that there was a strong positive correlation between pretreatment $\beta$-CIT binding and treatment response $\left(r=0.56 ; p<0.01^{* *}\right)$ (Figure $3 c$ ). The correlation remained significant when treatment response was expressed in percent $(r=0.64 ; p<0.001)$. Age, gender and age at onset of illness did not correlate significantly with the $\beta$-CIT ratios with either correlation. When correlating the individual percentage reduction of $\beta$-CIT ratios (occupancy) with treatment response, we observed a tendency towards a significant negative association $(r=-0.38$; $p=0.09$ ).

In search of predictors of treatment response, we included the following variables in another multiple linear regression analysis: subject's age, gender, age at onset of OCD, baseline Y-BOCS scores and baseline $\beta$-CIT-binding ratios. This statistical model revealed that only the pretreatment $\beta$-CITbinding ratios had significant impact on the treatment response $(\mathrm{B}=14.145 \pm 4.514 ; t=3.133 ; p=0.005)$. The result also remained stable when treatment response was expressed in percent $(B=67.046 \pm 17.149 ; \quad t=3.910$; $p=0.001$ ). These results demonstrated that higher pretreatment thalamic-hypothalamic SERT availability significantly predicted better treatment response 12 weeks later.

As pre- and posttreatment Y-BOCS scores and $\beta$-CITbinding ratios were involved in four different statistical inference procedures, the individual nominal $p$-values reported should be adjusted for multiple testing to obtain a more realistic quantification of the statistical significance of the relationships found. In our case, a simple yet possibly rather conservative Bonferroni correction (multiplication of
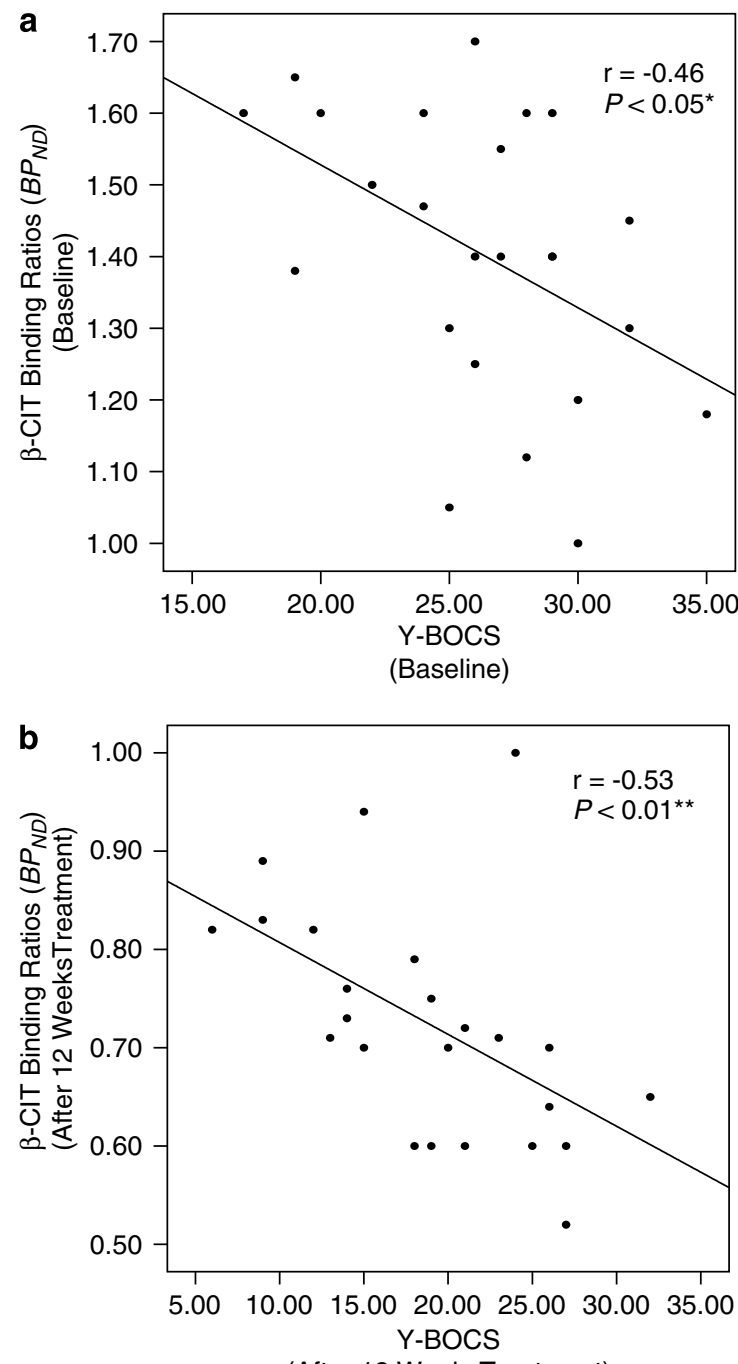

(After 12 WeeksTreatment)

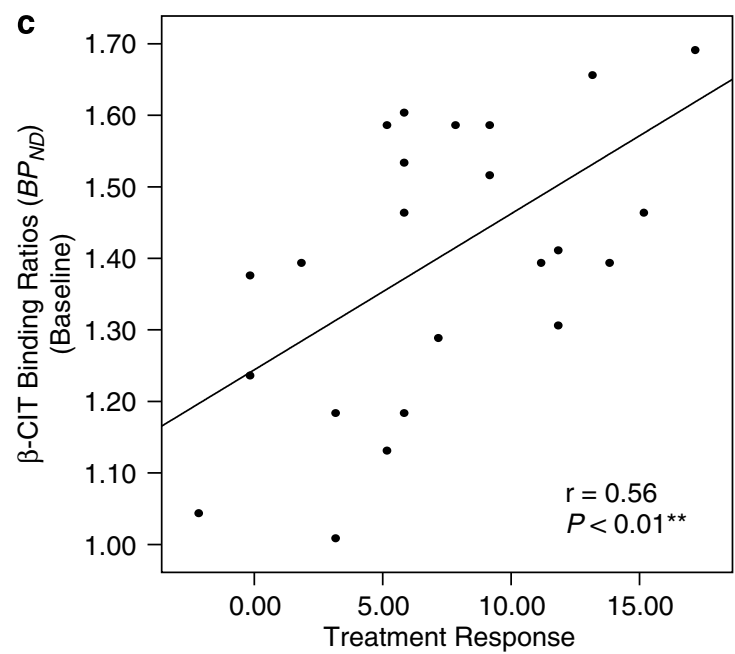

(Y-BOCS differences pre/post treatment)

Figure 3 (a) Correlations between serotonin transporter availability in thalamus-hypothalamus as measured by $B P_{N D}$ and severity of OC-symptomatology (Y-BOCS scores) in 24 OCD patients at baseline $\left(r=-0.46 ; p<0.05^{*}\right)$, and (b) after 12 weeks of treatment with clomipramine $(r=-0.53 ; p<0.0$ l**). (c) Correlation between serotonin transporter availability at baseline and treatment response $\left(r=0.56 ; p<0.0 I^{* * *}\right)$. 
the nominal $p$-values by four) can be performed, which in all cases leaves the tests significant at the $5 \%$ level.

\section{DISCUSSION}

Hitherto, changes in the central serotonergic systems were mainly investigated using the selective serotonin reuptake inhibitors (SSRIs). Reductions in [ $\left.{ }^{123} \mathrm{I}\right] \beta$-CIT binding with citalopram and paroxetine were consistent with their profile as SSRIs (Hyttel 1977, 1982) and considered to be the result of transporter occupancy. Pirker et al (1995) reported that SERT binding measured with $\left[{ }^{123} \mathrm{I}\right] \beta$-CIT was $45 \%$ lower in the hypothalamus/midbrain region of depressed patients taking citalopram (20-60 mg/day) compared with age- and gender-matched controls. Similarly, Kugaya et al (2003) showed a $39 \%$ reduction of $\beta$-CIT binding in the diencephalon in nine healthy human subjects treated with citalopram $40 \mathrm{mg} /$ day. Taken together these studies demonstrated that the extent of reduction of SERT availability caused by SSRIs in serotonin-rich brain regions is similar to that of clomipramine $(48 \%)$ in the present investigation. This suggests a similar mode of action of these medication groups in serotonergic neurons.

These findings are in line with results from PET studies on SERT occupancy using the selective ligands $\left[{ }^{11} \mathrm{C}\right] \mathrm{DASB}$ and $\left[{ }^{11} \mathrm{C}\right](+)$ McN5652 in major depression, social phobia and healthy volunteers showing similar degrees of SERT occupancy with SSRIs and clomipramine (Meyer et al, 2001; Kent et al, 2002; Suhara et al, 2003; Meyer et al, 2004). However, rates of SERT occupancy measured with these selective ligands are higher (about $80 \%$ ) than those measured with $\beta$-CIT SPECT, which may be explained by the non-selectivity of $\beta$-CIT and contribution of dopamine and norepinephrine transporter binding to the signal measured in SERT-rich brain regions (for review see Meyer, 2007).

Studies investigating the influence of the obsessivecompulsive disorder itself on SERT availability in untreated OCD patients produced conflicting results (Table 2): Simpson et al (2003) and van der Wee et al (2004) found no changes in SERT availability in the thalamus, midbrain or pons whereas Pogarell et al (2003) observed increased transporter availability in the midbrain-pons. Conversely, four further studies revealed reduced SERT availability: Stengler-Wenzke et al (2004) in the midbrain and brainstem and a trend in the thalamic-hypothalamic area, Hesse et al (2005) in the thalamus-hypothalamus, midbrain and brainstem, Reimold et al (2007) in the thalamus and midbrain, and Zitterl et al (2007) in the thalamushypothalamus using an independent sample (Table 2). The reasons for these differing results lie presumably in the inclusion of heterogeneous groups of OCD patients in most of the previous studies and, furthermore, in differences in ROIs, in methodologies and sample sizes. The final four of the above listed studies, which were also based on the largest number of patients on the whole, came to the conclusion that SERT availability in the thalamus-hypothalamus was reduced by $10-20 \%$ in untreated OCD patients as compared to healthy control subjects. A direct comparison of our patients ( $\beta$-CIT binding ratio 1.39 at baseline) with the healthy control subjects of the study of Zitterl et al (2007), in which the healthy control group had a $\beta$-CIT binding ratio of 1.69 , confirms this reduction. Taken together, we believe the reduction in SERT availability in our treated OCD patients is made up of the following two

Table 2 Neuroimaging of Serotonin Transporters in OCD Patients and Healthy Control Subjects

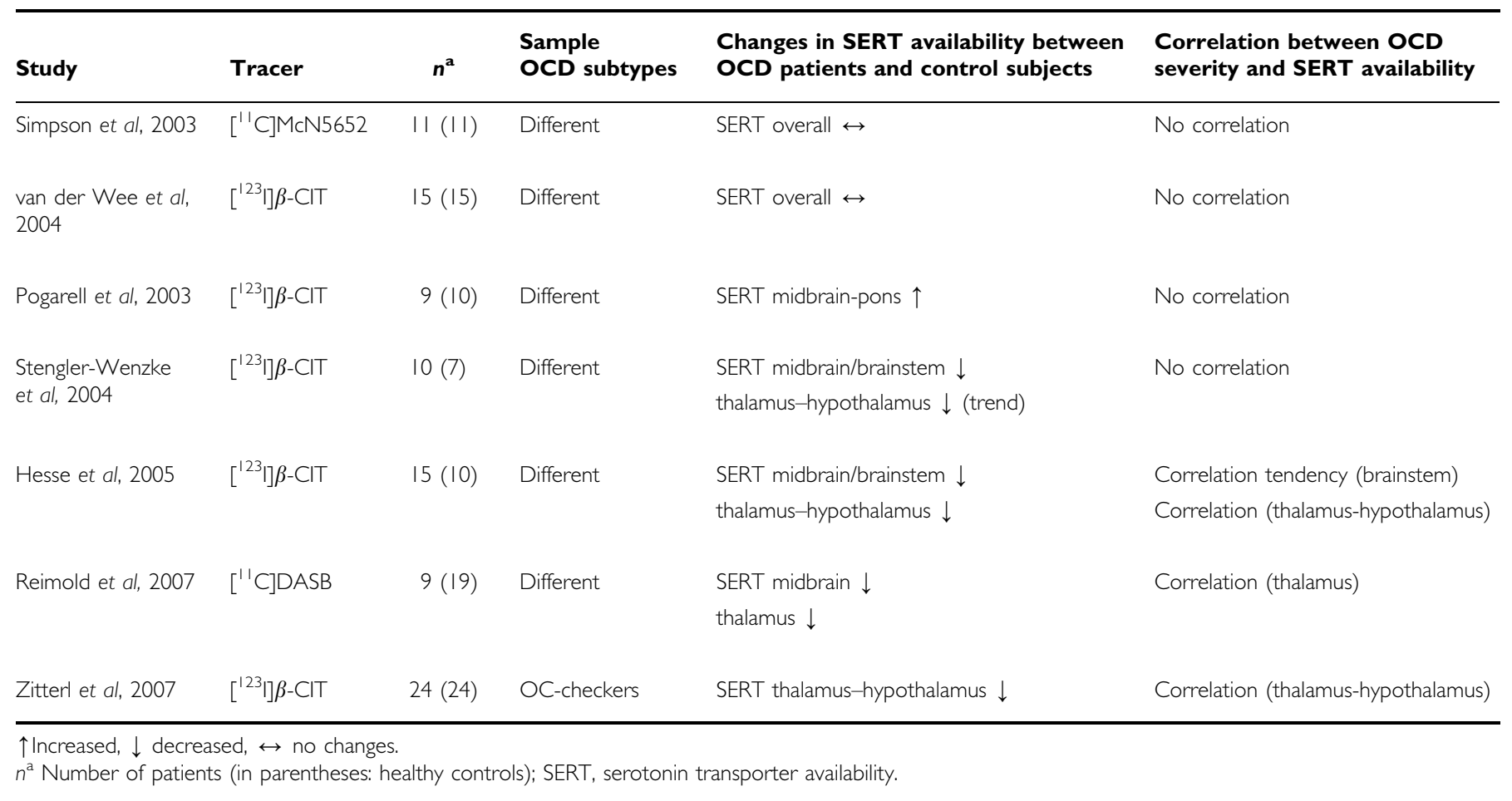


components: (1) compared to healthy control subjects a $10-20 \%$ reduction due to the OCD itself, which is presumably caused by downregulation of SERT by adaptive or compensatory regulation processes (Zitterl et al, 2007) and (2) a further reduction of $48 \%$ through clomipramine, which can be explained by occupancy by clomipramine similar to that of the SSRIs. Both components appear to have the objective of preserving or producing a high tone of intrasynaptic serotonin to counteract the OCD.

In our investigation we found a significant negative correlation between the severity of OC-symptomatology (Y-BOCS scores) and $\beta$-CIT binding both at baseline and after treatment with clomipramine. Correlations between pretreatment OCD severity and SERT binding were also calculated in seven previously mentioned $\beta$-CIT and PET studies (Table 2). However, in four of these investigations no significant correlations were found. Again one must keep in mind that these negative results are most likely dependent upon differences in ROIs, in methodologies and sample sizes. Most previous studies included heterogeneous groups of OCD patients reducing the chance of finding correlations related to a particular subtype of OCD for example with predominant checking compulsions. Moreover, there were considerable differences in severity of OCD among the patient groups as well. On the other hand, the results of the present study are confirmed by three recently published $\beta$-CIT and PET studies with untreated OCD patients: Hesse et al (2005), Reimold et al (2007) and Zitterl et al (2007) found significant negative associations between thalamic-hypothalamic SERT binding and obsessive-compulsive scores (Table 2).

A possible explanation for the similar results in treated subjects in the study at hand is that in our clomipramine patients, due to the medication, the entire level of $\beta$-CIT bindings was transposed to a lower level (compare Figure $3 \mathrm{a}$ and $b$ ). Thus, the correlation between the severity of OCsymptomatology and $\beta$-CIT binding would have been maintained even under medication. Low $\beta$-CIT values appeared to correlate to increasing degree of illness both before and after treatment and could thus be viewed as a biological indicator of disease severity. Up to now, the severity of OC-symptomatology could only be assessed on the basis of psychological tests for example the Y-BOCS. Based on our results, we may for the first time have access to a biological indicator, which, on the one hand, correlates with the Y-BOCS, yet, on the other hand, has the added advantage of assessing the severity of OC-symptomatology independent of the information provided by the patients themselves, thus eliminating their influence on the outcome. The subjective information provided by the patients could then be brought to a more objective level. To what extent the $\beta$-CIT values might be used as sole or additional parameter regarding course of illness such as in monitoring response to therapy remains to be investigated in further studies.

We obtained an unexpected result when correlating the treatment response with baseline $\beta$-CIT-binding ratios. Patients whose Y-BOCS scores improved more during the 3 months of treatment showed highly significant higher $\beta$-CIT bindings at baseline. Using multiple linear regression analyses we were able to demonstrate that higher pretreatment $\beta$-CIT binding predicted better short-term treatment response to clomipramine. Taken together, these results suggest that the level of availability of serotonin transporters in the thalamus-hypothalamus may be both a biological marker for the severity of OCD (less availability of SERT at baseline associated with more severe OCD) and a predictor of treatment response (higher availability of SERT at baseline associated with greater treatment response).

In our study, we observed a tendency towards a significant negative association between the individual percentage reduction of $B P_{\mathrm{ND}}$ (occupancy) and treatment response. This result is inconsistent with a pilot $\beta$-CIT study involving five OCD patients by Stengler-Wenzke et al (2006) who found a positive association between individual SERT occupancy by citalopram and clinical response after 1 year of treatment. However, we cannot compare the results of this pilot study with our findings as: (1) in the study of Stengler-Wenzke it was not possible to differentiate the effects of SSRI treatment and complementary interventions because all five patients attended an OCD outpatient program including elements of cognitive-behavior therapy and psychoeducation; and (2) statistical calculations based on only five patients are unreliable. Future studies using selective ligands may help to clarify the relationship between SERT occupancy and treatment response in OCD.

In conclusion, the present study is to our knowledge the first direct documentation of the serotonin transporter blocking properties of clomipramine in the human brain in vivo by means of $\beta$-CIT and SPECT. Consistent with one previous in vitro report, therapeutic doses of clomipramine induced about $50 \%$ reduction in activity of $\left[{ }^{123} \mathrm{I}\right] \beta$-CIT in the thalamic-hypothalamic region. One central finding was that pretreatment $\beta$-CIT-binding values can be considered a predictor of treatment response. Further studies, in which the $\beta$-CIT-binding values during a longer treatment period are repeatedly tested, are necessary to be able to assess the role of this predictor for the clinical course of OCD.

\section{DISCLOSURE/CONFLICT OF INTEREST}

The authors declare that, except for income received from each respective primary employer, no financial support or compensation has been received from any individual or corporate entity over the past 3 years for research or professional service and there are no personal financial holdings that could be perceived as constituting a potential conflict of interest.

\section{REFERENCES}

American Psychiatric Association (1994). Diagnostic and Statistical Manual of Mental Disorders. 4th edn. American Psychiatric Press: Washington, DC.

Angst J, Gamma A, Endrass J, Goodwin R, Ajdacic V, Eich D et al. (2004). Obsessive-compulsive severity spectrum in the community: prevalence, comorbidity, and course. Eur Arch Psychiatry Clin Neurosci 254: 156-164.

Bäckström I, Bergström M, Marcusson J (1989). High affinity $\left[{ }^{3} \mathrm{H}\right]$ paroxetine binding to serotonin uptake sites in human brain tissue. Brain Res 486: 261-268.

Baumgarten HG, Grozdanovic Z (1998). Role of serotonin in obsessive-compulsive disorder. Br J Psychiatry 35(suppl): 13-20. 
Boja JW, Mitchell WM, Patel A, Kopajtic TA, Carroll FI, Lewin AH et al (1992). High-affinity binding of $\left[{ }^{125} \mathrm{I}\right] \mathrm{RTI}-55$ to dopamine and serotonin transporters in rat brain. Synapse 12: 27-36.

Brücke T, Kornhuber J, Angelberger P, Asenbaum S, Frassine H, Podreka I (1993). SPECT imaging of dopamine and serotonin transporters with $\left[{ }^{123} \mathrm{I}\right] \beta$-CIT. Binding kinetics in the human brain. J Neural Transm Gen Sect 94: 137-146.

De Keyser J, De Backer JP, Ebinger G, Vauquelin G (1989). $\left[{ }^{3} \mathrm{H}\right] \mathrm{GBR}-12935$ binding to dopamine uptake sites in the human brain. J Neurochem 53: 1400-1404.

First MB, Spitzer RL, Gibbon M, Williams JBW (1996). User's Guide for the Structured Clinical Interview for DSM-IV Axis 1 Disorders: SCID-1 Clinician Version. American Psychiatric Press: Washington, DC.

Fujita M, Takatoku K, Matoba Y, Nishiura M, Kobayashi K, Inoue O et al (1997). Enhancement of [ $\left.{ }^{123} \mathrm{I}\right] \beta$-CIT binding in the striatum with clomipramine: is there a serotonin-dopamine interaction? Eur J Nucl Med 24: 403-408.

Goodman WK (1999). Obsessive-compulsive disorder: diagnosis and treatment. J Clin Psychiatry 60(suppl 18): 27-32.

Goodman WK, McDougle CJ, Price LH (1992). The role of serotonin and dopamine in the pathophysiology of obsessivecompulsive disorder. Int Clin Psychopharmacol 7(suppl 1): 35-38.

Goodman WK, Price LH, Delgado PL, Palumbo J, Krystal JH, Nagy LM et al (1990). Specificity of serotonin reuptake inhibitors in the treatment of obsessive-compulsive disorder. Comparison of fluvoxamine and desipramine. Arch Gen Psychiatry 47: 577-585.

Goodman WK, Price LH, Rasmussen SA, Mazure C, Delgado P, Heninger GR et al (1989b). The Yale-Brown Obsessive Compulsive Scale. II. Validity. Arch Gen Psychiatry 46: 1012-1016.

Goodman WK, Price LH, Rasmussen SA, Mazure C, Fleischmann RL, Hill CL et al (1989a). The Yale-Brown Obsessive Compulsive Scale. I. Development, Use, and Reliability. Arch Gen Psychiatry 46: 1006-1011.

Hamilton M (1960). A rating scale for depression. J Neurol Neurosurg Psychiatry 23: 56-62.

Heinz A, Knable MB, Wolf SS, Jones DW, Gorey JG, Hyde TM et al (1998a). Tourette's syndrome: [I-123] $\beta$-CIT SPECT correlates of vocal tic severity. Neurology 51: 1069-1074.

Heinz A, Ragan P, Jones DW, Hommer D, Williams W, Knable MB et al (1998b). Reduced central serotonin transporters in alcoholism. Am J Psychiatry 155: 1544-1549.

Hesse S, Müller U, Lincke T, Barthel H, Villmann T, Angermeyer MC et al (2005). Serotonin and dopamine transporter imaging in patients with obsessive-compulsive disorder. Psychiatry Res: Neuroimaging 140: 63-72.

Hollander E, DeCaria CM, Nitescu A, Gully R, Suckow RF, Cooper TP et al (1992). Serotonergic function in obsessive-compulsive disorder. Behavioral and neuroendocrine responses to oral $\mathrm{m}$-chlorophenylpiperazine and fenfluramine in patients and healthy volunteers. Arch Gen Psychiatry 49: 21-28.

Horwath E, Weissman M (2000). The epidemiology and crossnational presentation of obsessive-compulsive disorder. Psychiatr Clin North Am 23: 493-507.

Hyttel J (1977). Neurochemical characterization of a new potent and selective serotonin uptake inhibitor: Lu 10-171. Psychopharmacology 51: 225-233.

Hyttel J (1982). Citalopram: pharmacological profile of a specific serotonin uptake inhibitor with antidepressant activity. Prog Neuropsychopharmacol Biol Psychiatry 6: 277.

Innis R, Baldwin R, Sybirska E, Zea Y, Laruelle M, Al-Tikriti M et al (1991). Single photon emission computed tomography imaging of monoamine reuptake sites in primate brain with $\left[{ }^{123} \mathrm{I}\right]$ B-CIT. Eur J Pharmacol 200: 369-370.

Innis R, Cunningham V, Delforge J, Fujita M, Gjedde A, Gunn R et al (2007). Consensus nomenclature for in vivo imaging of reversibly binding radioligands. I Cereb Blood Flow Metab 27: 1533-1539.

Insel TR (1992). Toward a neuroanatomy of obsessive-compulsive disorder. Arch Gen Psychiatry 49: 739-744.

Jacobsen LK, Staley JK, Malison RT, Zoghbi SS, Seibyl JP, Kosten TR et al (2000). Elevated central serotonin transporter binding availability in acutely abstinent cocaine-dependent patients. Am J Psychiatry 157: 1134-1140.

Kasper S, Tauscher J, Willeit M, Stamenkovic M, Neumeister A, Küfferle B et al (2002). Receptor and transporter imaging studies in schizophrenia, depression, bulimia and Tourette's disorder -implications for psychopharmacology. World J Biol Psychiatry 3: $133-146$.

Kent JM, Coplan JD, Lombardo I, Hwang DR, Huang Y, Mawlawi O et al (2002). Occupancy of brain serotonin transporters during treatment with paroxetine in patients with social phobia: a positron emission tomography study with $\left[{ }^{11} \mathrm{C}\right] \mathrm{McN} 5652$. Psychopharmacology 164: 341-348.

Kugaya A, Seneca NM, Snyder PJ, Williams SA, Malison RT, Baldwin RM et al (2003). Changes in human in vivo serotonin and dopamine transporter availabilities during chronic antidepressant administration. Neuropsychopharmacology 28: 413-420.

Kuikka JT, Bergström KA, Vanninen E, Laulumaa V, Hartikainen P, Länsiemies E (1993). Initial experience with single photon emission tomography using iodine-123-labelled $2 \beta$-carbomethoxy-3 $\beta$-(4-iodophenyl)tropane in human brain. Eur $\mathrm{J} \mathrm{Nucl}$ Med 20: 783-786.

Laruelle M, Wallace E, Seibyl JP, Zea-Ponce Y, Zoghbi SS, Neumeyer JL et al (1994). Graphical, kinetic, and equilibrium analyses of in vivo [ $\left.{ }^{123} \mathrm{I}\right]$ - $\beta$-CIT binding to dopamine transporters in healthy human subjects. J Cereb Blood Flow Metab 14: 982-994.

Leonard H, Swedo S, Rapoport JL, Coffey M, Cheslow D (1988). Treatment of childhood obsessive-compulsive disorder with clomipramine and desmethylimipramine: a double-blind crossover comparison. Psychopharmacol Bull 24: 93-95.

Malison RT, Price LH, Berman R, van Dyck CH, Pelton GH, Carpenter L et al (1998). Reduced brain serotonin transporter availability in major depression as measured by $\left[{ }^{123} \mathrm{I}\right]-2 \beta$ carbomethoxy-3 $\beta$-(4-iodophenyl)tropane and single photon emission computed tomography. Biol Psychiatry 44: 1090-1098.

McTavish D, Benfield P (1990). Clomipramine. An overview of its pharmacological properties and a review of its therapeutic use in obsessive-compulsive disorder and panic disorder. Drugs 39: 136-153.

Meyer JH (2007). Imaging the serotonin transporter during major depressive disorder and antidepressant treatment. J Psychiatry Neurosci 32: 86-102.

Meyer JH, Wilson AA, Ginovart N, Goulding V, Hussey D, Hood K et al. (2001). Occupancy of serotonin transporters by paroxetine and citalopram during treatment of depression: a $\left[{ }^{11} \mathrm{C}\right] \mathrm{DASB}$ PET imaging study. Am J Psychiatry 158: 1843-1849.

Meyer JH, Wilson AA, Sagrati S, Hussey D, Carella A, Potter WZ et al (2004). Serotonin transporter occupancy of five selective serotonin reuptake inhibitors at different doses: an $\left[{ }^{11} \mathrm{C}\right] \mathrm{DASB}$ positron emission tomography study. Am J Psychiatry 161: 826-835.

Mintun M, Raichle M, Kolbourn M, Wooten G, Welch M (1984). A quantitative model for the in vivo assessment of drug binding sites with positron emission tomography. Ann Neurol 15: 217-227.

Neumeyer JL, Wang S, Milius RA, Baldwin RM, Zea-Ponce Y, Hoffer PB et al (1991). [ $\left.{ }^{123} \mathrm{I}\right]-2 \beta$-carbomethoxy-3 $\beta$-(4-iodophenyl)tropane $(\beta$-CIT): high-affinity SPECT radiotracer of monoamine reuptake sites in brain. J Med Chem 34: 3144-3146.

Pirker W, Asenbaum S, Hauk M, Kandlhofer S, Tauscher J, Willeit M et al (2000). Imaging serotonin and dopamine transporters 
with ${ }^{123}$ I- $\beta$-CIT SPECT: binding kinetics and effects of normal aging. J Nucl Med 41: 36-44.

Pirker W, Asenbaum S, Kasper S, Walter H, Angelberger P, Koch G et al (1995). $\beta$-CIT SPECT demonstrates blockade of 5-HT uptake sites by citalopram in the human brain in vivo. J Neural Transm Gen Sect 100: 247-256.

Pogarell O, Hamann C, Pöpperl G, Juckel G, Choukèr M, Zaudig M et al (2003). Elevated brain serotonin transporter availability in patients with obsessive-compulsive disorder. Biol Psychiatry 54: 1406-1413.

Prichep LS, Mas F, Hollander E, Liebowitz M, John ER, Almas M et al (1993). Quantitative electroencephalographic subtyping of obsessive-compulsive disorder. Psychiatry Res 50: 25-32.

Reimold M, Smolka M, Zimmer A, Batra A, Knobel A, Solbach C et al (2007). Reduced availability of serotonin transporters in obsessive-compulsive disorder correlates with symptom severity-a $\left[{ }^{11} \mathrm{C}\right]$ DASB PET study. J Neural Transm 114: 1603-1609.

Saxena S, Brody AL, Schwartz JM, Baxter LR (1998). Neuroimaging and frontal-subcortical circuitry in obsessive-compulsive disorder. Br J Psychiatry 35(suppl): 26-37.

Saxena S, Rauch SL (2000). Functional neuroimaging and the neuroanatomy of obsessive-compulsive disorder. Psychiatr Clin North Am 23: 563-586.

Simpson HB, Lombardo I, Slifstein M, Huang HY, Hwang DR, Abi-Dargham A et al (2003). Serotonin transporters in obsessive-compulsive disorder: a positron emission tomography study with $\left[{ }^{11} \mathrm{C}\right] \mathrm{McN}$ 5652. Biol Psychiatry 54: 1414-1421.

Stein DJ (2002). Obsessive-compulsive disorder. Lancet 360: 397-405.

Stein MB, Forde DR, Anderson G, Walker JR (1997). Obsessivecompulsive disorder in the community: an epidemiologic survey with clinical reappraisal. Am J Psychiatry 154: 1120-1126.

Stengler-Wenzke K, Müller U, Angermeyer MC, Sabri O, Hesse S (2004). Reduced serotonin transporter-availability in obsessivecompulsive disorder (OCD). Eur Arch Psychiatry Clin Neurosci 254: $252-255$.
Stengler-Wenzke K, Müller U, Barthel H, Angermeyer MC, Sabri O, Hesse S (2006). Serotonin transporter imaging with $\left[{ }^{123} \mathrm{I}\right] \beta$-CIT SPECT before and after one year of citalopram treatment of obsessive-compulsive disorder. Neuropsychobiology 53: 40-45.

Suhara T, Takano A, Sudo Y, Ichimiya T, Inoue M, Yasuno F et al (2003). High levels of serotonin transporter occupancy with lowdose clomipramine in comparative occupancy study with fluvoxamine using positron emission tomography. Arch Gen Psychiatry 60: 386-391.

Talairach J, Tournoux P (1988). Coplanar Stereotaxic Atlas of the Human Brain. Thieme Medical: New York, NY.

Tauscher J, Pirker W, Willeit $M$, de Zwaan M, Bailer $U$, Neumeister A et al (2001). [ $\left.{ }^{123} \mathrm{I}\right] \quad \beta$-CIT and single photon emission computed tomography reveal reduced brain serotonin transporter availability in bulimia nervosa. Biol Psychiatry 49: 326-332.

van der Wee NJ, Stevens H, Hardeman JA, Mandl RC, Denys DA, van Megen HJ et al (2004). Enhanced dopamine transporter density in psychotropic-naive patients with obsessive-compulsive disorder shown by $\left[{ }^{123} \mathrm{I}\right] \beta$-CIT SPECT. Am J Psychiatry 161: 2201-2206.

Vythilingum B, Cartwright C, Hollander E (2000). Pharmacotherapy of obsessive-compulsive disorder: experience with the selective serotonin reuptake inhibitors. Int Clin Psychopharmacol 15(suppl 2): S7-S13.

Willeit M, Praschak-Rieder N, Neumeister A, Pirker W, Asenbaum S, Tauscher $\mathrm{J}$ et al (2000). $\left[{ }^{123} \mathrm{I}\right]-\beta$-CIT SPECT imaging shows reduced brain serotonin transporter availability in drug-free depressed patients with seasonal affective disorder. Biol Psychiatry 47: 482-489.

Zitterl W, Aigner M, Stompe T, Zitterl-Eglseer K, Gutierrez-Lobos K, Schmidl-Mohl B et al (2007). $\left[{ }^{123} \mathrm{I}\right]-\beta$-CIT SPECT imaging shows reduced thalamus-hypothalamus serotonin transporter availability in 24 drug-free obsessive-compulsive checkers. Neuropsychopharmacology 32: 1661-1668. 